\title{
Surgical Management of Suspicious Melanocytic Lesions in Italy
}

\author{
Vincenzo De Giorgi ${ }^{a}$ Paolo Ascierto ${ }^{b}$ Riccardo Bono ${ }^{c}$ Nicola Pimpinelli ${ }^{a}$ \\ Vanna Chiarion-Sileni ${ }^{d}$ Giuseppe Palmierie Maria Antonietta Pizzichetta ${ }^{f}$ \\ Alessandro Testorig Ignazio Stanganelli ${ }^{\text {h }}$ \\ ${ }^{a}$ Dermatologic Clinic, University of Florence, Florence, ${ }^{b}$ IRCCS National Cancer Institute, Naples, ${ }^{\mathrm{C}}$ Immacolata \\ Dermatological Institute, IRCCS, Rome, dVeneto Institute of Oncology, Padua, e Genetica Oncologica, CNR, Sassari, \\ ${ }^{f}$ Centro di Riferimento Oncologico, Aviano, ${ }^{9}$ Istituto Europeo di Oncologia, Milan, and ${ }^{\mathrm{h}}$ Istituto Scientifico \\ Romagnolo per lo Studio e la Cura dei Tumori, IRCCS IRST, Meldola, Italy
}

\section{Key Words}

Melanoma $\cdot$ Nevi $\cdot$ Incisional biopsy $\cdot$ Excisional biopsy .

Sentinel lymph node $\cdot$ Surgery $\cdot$ Treatment of melanoma

\begin{abstract}
Objective: In melanoma, the surgical approach is important for both diagnosis and therapy. Although surgery is relatively simple, the methods should be performed by experts in melanoma management. We analyze the techniques and methods used in the Italian hospital network for suspicious skin lesions and confirmed melanomas. Methods: A nationwide survey was conducted of a representative sample of 120 hospitals with $\geq 200$ beds. Results: Excision biopsies remove suspected melanomas. However, some approaches to excision margins and sentinel lymph node procedures differ from international protocols. Overall, $21 \%$ of centers perform excisional biopsy of a suspicious lesion using $1 \mathrm{~cm}$ margins, and $22 \%$ of centers perform sentinel node procedures concurrently with removal of primary melanoma. Conclusions: Standardized treatment protocols are needed for suspicious lesions and clinically evident melanoma, particularly regarding the critical aspect of excision margins. The sentinel lymph node procedure may be distorted by initial margins that are too wide.

Copyright $\odot 2013$ S. Karger AG, Basel
\end{abstract}

(c) 2013 S. Karger AG, Base

$1018-8665 / 13 / 2265-0018 \$ 38.00 / 0$

\section{Introduction}

Surgery plays an essential role in the management of melanoma and, in the absence of other effective treatment, is the only valid therapeutic and diagnostic procedure. Although surgery is relatively simple, methods such as incisional, excisional and punch biopsies as well as sentinel lymph node (SNL) procedures should be performed by a melanoma expert [1-3]. The decision to remove a suspicious melanocytic lesion depends on the clinical history and general condition of the patient, clinical-instrumental evaluation of the lesion and the degree of suspicion, as well as the clinician's expertise with melanoma. Biopsy techniques most often used in dermatology are incisional (circular or elliptical punch biopsy), shave and excisional biopsies. Incisional biopsy is generally unadvisable in melanocytic lesions, but a review of the literature reveals no survival difference according to biopsy methods. All national and international guidelines strongly recommend excisional biopsy whenever possible [4-6], because a definitive diagnosis is difficult in partially excised lesions, especially if the sample contains no healthy tissue [5]. Histopathologically confirmed melanoma requires SNL biopsy as a staging procedure.

\section{KARGER}

E-Mail karger@karger.com

www.karger.com/drm
Maria A. Pizzichetta, MD

Division of Medical Oncology C, Preventive Oncology

Centro di Riferimento Oncologico, IRCCS

Via Franco Gallini 2, IT-33081 Aviano (Italy)

E-Mail pizzichetta@cro.it 
We analyze the use of different surgical techniques and methods for clinically suspicious skin lesions and confirmed melanoma in the Italian hospital network. We also surveyed surgical margins before and after histopathology, patient selection criteria and surgical techniques for SNL procedures.

\section{Methods}

Briefly, a nationwide survey of clinicians responsible for the diagnosis, therapy or follow-up phases of melanoma care in Italian hospitals was conducted. Italian hospitals with $\geq 200$ beds $(n=285)$ were subdivided into 145 hospitals with $200-399$ beds and 140 hospitals with $\geq 400$ beds and a proportionally stratified random sample ( $\mathrm{n}=120$ centers), stratified by number of beds and geographic distribution, was selected. Two or three clinicians were interviewed at each center, resulting in approximately 250 interviews and a predicted margin of error - $95 \%$ confidence level - of $7.7 \%$.

Based on the findings, centers were grouped by number of new melanoma diagnoses per year into low- and high-volume centers, around the median value of 25 . Variables were analyzed in the total sample/total Italian hospitals, and comparisons were made between high- and low-volume centers using Pearson's $\chi^{2}$ test and the zeta test at $95 \%$ confidence level. Detailed methods are presented elsewhere in this supplement [7].

\section{Results}

Analysis of the frequency with which the most important surgical procedures (incisional biopsy, punch biopsy, shave biopsy and excisional biopsy) are used reveals that in $50 \%$ of hospitals excisional biopsy is 'always performed', while in the remainder of hospitals it is performed 'whenever possible'. There was no difference between high- and low-volume centers. Management of suspicious pigmented lesions and surgical treatment of primitive melanoma are summarized in table 1.

Regarding excision margins, most high-volume centers perform excisional biopsy with 1-2 $\mathrm{mm}$ margins ( $58 \%$ vs. low-volume hospitals $35 \%$; $\mathrm{p}=0.001$ ), whereas low-volume hospitals prefer excisional biopsy with $5 \mathrm{~mm}$ margins (high-volume hospitals $24 \%$ vs. low-volume hospitals $42 \%$; $\mathrm{p}=0.01$ ) (table 2 ). Excisional biopsy margins of $1 \mathrm{~cm}$ are preferred in $21 \%$ of centers, and there is no statistically significant difference between high- and lowvolume centers. When excisional biopsy is not possible, incisional biopsy is performed as described below.

Overall, $40 \%$ of hospitals do not perform incisional punch biopsies (table 1), and there is a significant differ-
Table 1. Type of biopsy used in Italian hospitals grouped according to yearly melanoma diagnoses into high-volume $(>25)$ and low-volume $(\leq 25)$ centers

\begin{tabular}{|c|c|c|c|}
\hline \multirow[t]{2}{*}{ Type of biopsy } & \multicolumn{3}{|c|}{ Type of center } \\
\hline & $\begin{array}{l}\text { high- } \\
\text { volume } \\
(\mathrm{n}=56)\end{array}$ & $\begin{array}{l}\text { low- } \\
\text { volume } \\
(\mathrm{n}=58)\end{array}$ & $\begin{array}{l}\text { all } \\
(\mathrm{n}=114)\end{array}$ \\
\hline \multicolumn{4}{|l|}{ Punch } \\
\hline Never & $22 \%$ & $58 \% *$ & $40 \%$ \\
\hline Particular cases & $54 \% *$ & $19 \%$ & $36 \%$ \\
\hline Large lesions & $13 \%$ & $9 \%$ & $11 \%$ \\
\hline Diagnosis confirmation & $7 \%$ & $2 \%$ & $5 \%$ \\
\hline Always & $4 \%$ & $12 \%$ & $8 \%$ \\
\hline \multicolumn{4}{|l|}{ Shaving } \\
\hline Never & $63 \%$ & $65 \%$ & $64 \%$ \\
\hline Particular cases & $54 \%$ & $21 \%$ & $16 \%$ \\
\hline Large lesions & $13 \%$ & $0 \%$ & $9 \%$ \\
\hline Diagnosis confirmation & $6 \%$ & $0 \%$ & $3 \%$ \\
\hline Always & $5 \%$ & $6 \%$ & $6 \%$ \\
\hline Not indicated & $2 \%$ & $2 \%$ & $2 \%$ \\
\hline \multicolumn{4}{|l|}{ Excisional } \\
\hline Never & $0 \%$ & $0 \%$ & $0 \%$ \\
\hline Whenever possible & $56 \%$ & $44 \%$ & $50 \%$ \\
\hline Always & $44 \%$ & $56 \%$ & $50 \%$ \\
\hline
\end{tabular}

ence between high- and low-volume hospitals (22 vs. $58 \%$; $<0.001)$. They are performed mainly for lentigo on the face, where there was a significant difference between high- and low-volume hospitals (54 vs. 19\%; p < 0.001 ; average $36 \%$ ). There is no statistically significant difference between high- and low-volume hospitals regarding other indications (table 1 ).

A majority of hospitals (64\%) do not perform shave biopsies. When they are used it is for (1) special cases (16\%), (2) large lesions (9\%), (3) confirmation of clinical diagnoses $(6 \%)$ or (4) always (6\%). Two percent of hospitals did not provide information on the use of shave biopsies.

Surgical removal of clinically evident melanomas (before histological examination) is approached in several ways (table 3 ). The definition of complete removal includes 1-2 mm margins in 10\% of centers, $5 \mathrm{~mm}$ margins in $16 \%$ and $1 \mathrm{~cm}$ margins in $38 \%$. Importantly, $22 \%$ of hospitals define complete removal as margins $\geq 1 \mathrm{~cm}$ and SNL biopsy. There was no statistically significant difference between high- and low-volume hospitals (27 vs. $18 \%$ ). Radical removal after incisional biopsy is used in $19 \%$ of high-volume hospitals and in $8 \%$ of low-volume hospitals. 
Table 2. Surgical margins used for taking incisional biopsies in Italian hospitals, grouped according to yearly melanoma diagnoses into high-volume $(>25)$ and low-volume $(\leq 25)$ centers

\begin{tabular}{llll}
\hline Margin & \multicolumn{2}{l}{ Type of center } \\
\cline { 2 - 4 } & $\begin{array}{l}\text { high-volume } \\
(\mathrm{n}=56)\end{array}$ & $\begin{array}{l}\text { low-volume } \\
(\mathrm{n}=58)\end{array}$ & $\begin{array}{l}\text { all } \\
(\mathrm{n}=114)\end{array}$ \\
\hline $1-2 \mathrm{~mm}$ & $58 \% *$ & $35 \%$ & $46 \%$ \\
$5 \mathrm{~mm}$ & $24 \%$ & $42 \% * *$ & $33 \%$ \\
$10 \mathrm{~mm}$ & $18 \%$ & $23 \%$ & $21 \%$ \\
\hline
\end{tabular}

${ }^{*} \mathrm{p}=0.001{ }^{* *} \mathrm{p}=0.01$

Table 3. Mode of removal of clinically evident melanomas before histology results are known in Italian hospitals that perform biopsies grouped according to yearly melanoma diagnoses into highvolume $(>25)$ and low-volume $(\leq 25)$ centers

\begin{tabular}{lrrl}
\hline Method (margins) & \multicolumn{3}{l}{ Type of center } \\
\cline { 2 - 4 } & $\begin{array}{l}\text { high- } \\
\text { volume } \\
(\mathrm{n}=56)\end{array}$ & $\begin{array}{l}\text { low- } \\
\text { volume } \\
(\mathrm{n}=58)\end{array}$ & all \\
& $7 \mathrm{n}=114)$ \\
\hline Complete $(1-2 \mathrm{~mm})$ & $16 \%$ & $13 \%$ & $10 \%$ \\
Complete $(5 \mathrm{~mm})$ & $31 \%$ & $45 \%$ & $38 \%$ \\
Complete $(10 \mathrm{~mm})$ & $27 \%$ & $18 \%$ & $22 \%$ \\
Complete $(10 \mathrm{~mm})$ with SNL biopsy & $19 \%$ & $8 \%$ & $14 \%$ \\
Radical excision after incisional biopsy & $19 \%$ & & \\
\hline
\end{tabular}

\section{Discussion}

Excisional biopsy 'always' or 'whenever possible' for suspicious melanocytic lesions is common practice among Italian hospitals and in line with the recommendations of all national and international organizations. The choice of complete removal - 'always' as reported by $50 \%$ of centers - requires some careful consideration as there are cases in whom a particular location and/or extension of the lesion necessitate diagnostic certainty before complete excision is performed. It is possible that the use of non-invasive diagnostic techniques such as dermoscopy, which is more common in Italy than in other countries, permits such an approach. On the other hand, wide excision in aesthetically critical areas would be ethically questionable and objectionable to the patient if histological examination reveals that the lesion was benign. Concerning excision margins, most high-volume hospitals perform excisional biopsy with a $1-2 \mathrm{~mm}$ margin, whereas low-volume hospitals prefer to use $5 \mathrm{~mm}$ margins. The reason for this difference is not clear, but it is apparently not critical as both are in line with recommendations reported in the literature [8-11]. Particularly outstanding is the fact that $21 \%$ of centers choose to perform excisional biopsy with $1 \mathrm{~cm}$ margins in case of suspicious lesions. This approach is not completely justified, as it may be considered overtreatment, considering the possible post-surgical implications if diagnosis of melanoma is not confirmed or if melanoma is diagnosed with an extension of $>1 \mathrm{~cm}$ with relative SNL changes [12-14]. This approach may result from greater confidence in the diagnosis of a melanocytic lesion with peculiar clinical and dermoscopic features, which leads clinicians to convince their patients to undergo radical surgery ab initio. In cases where excisional biopsy is not possible for aesthetic or practical reasons or because of the patient's general health, incisional punch biopsy rather than shave biopsy is often used for diagnosis.

Another noteworthy finding of the national Melanoma Task Force (META) survey concerns the surgical management of clinically evident melanoma. Complete removal with $1 \mathrm{~cm}$ margins, with or without a SNL procedure, is performed before histological examination in nearly two thirds of hospitals (table 3). This level of diagnostic confidence obviously requires some careful consideration, particularly regarding the choice to perform SNL procedure without adequate staging. On average $22 \%$ of hospitals perform SNL procedures (27\% in highvolume hospitals and $18 \%$ in low-volume hospitals) concurrently with removal of the primary melanoma, an approach that needs correction in light of current international protocols $[13,14]$. Excision with 1-5 mm margins, as recommended in the guidelines, is performed in only $26 \%$ of the Italian hospitals surveyed.

We found that radical excision is performed after incisional biopsy in $14 \%$ of centers. This deserves further consideration, particularly if it is not associated with facial or large lesions. Punch or shave biopsies are performed in both high- and low-volume hospitals, either in all cases or to confirm a diagnosis. Incisional biopsy (punch or shave) is performed in most high-volume centers, whereas most of the low-volume centers do not perform these procedures. Punch procedures are performed in more high-volume centers, probably due to the availability of dermatology services with more experience with this procedure. Some centers perform shave biopsy, most likely to provide histological confirmation of a benign diagnosis in selected cases. However, since the survey question addressed suspicious melanocytic lesions, this result should prompt further reflection. 
In conclusion, our findings should inspire the national scientific authorities to establish more uniform treatment protocols for managing clinically suspicious lesions and confirmed cases of melanoma, particularly regarding excision margins, an important aspect that can compromise future SNL procedures if initial margins are too wide.

\section{Disclosure Statement}

The authors received no funding and report no conflict of interest.

\section{References}

1 Thompson JF, Scolyer RA, Kefford RF: Cutaneous melanoma. Lancet 2005;365:687-701.

2 Thirlwell C, Nathan P: Melanoma - part 2: management. BMJ 2008;337:a2488.

- 3 Tsao H, Atkins MB, Sober AJ: Management of cutaneous melanoma. N Engl J Med 2004;351: 998-1012.

4 Tran KT, Wright NA, Cockerell CJ: Biopsy of the pigmented lesion - when and how. J Am Acad Dermatol 2008;59:852-871.

5 Montgomery BD, Sadler GM: Punch biopsy of pigmented lesions is potentially hazardous. Can Fam Physician 2009;55:24.

-6 Roberts DL, Anstey AV, Barlow RJ, Cox NH, Newton Bishop JA, Corrie PG, Evans J, Gore ME, Hall PN, Kirkham N; British Association of Dermatologists; Melanoma Study Group: U.K. guidelines for the management of cutaneous melanoma. Br J Dermatol 2002;146:717.
7 Mingozzi E, Fregosi S, Gandini S, Stanganelli I, Chiarion-Sileni V, Testori A: Melanoma Task Force (META) project in Italy: methodology. Dermatology 2013;226(suppl 1): $1-2$.

8 Australian Cancer Network: The management of cutaneous melanoma. Clinical practice guidelines. Canberra, National Health and Medical Research Council, 1999. http:// www.nhmrc.gov.au/guidelines/publications/ cp68 (accessed April 2012).

$\rightarrow$ Cook J: Surgical margins for resection of primary cutaneous melanoma. Clin Dermatol 2004;22:228-233.

10 Haigh PI, DiFronzo LA, McCready DR: Optimal excision margins for primary cutaneous melanoma: a systematic review and metaanalysis. Can J Surg 2003;46:419-426.
11 Veronesi U, Cascinelli N: Narrow excision (1-cm margin). A safe procedure for thin cutaneous melanoma. Arch Surg 1991;126: 438-441.

12 Easson AM, Rotstein LE, McCready DR: Lymph node assessment in melanoma. J Surg Oncol 2009;99:176-185.

13 Amersi F, Morton DL: The role of sentinel lymph node biopsy in the management of melanoma. Adv Surg 2007;41:241-256.

$\checkmark 14$ Balch CM, Soong SJ, Atkins MB, Buzaid AC, Cascinelli N, Coit DG, Fleming ID, Gershenwald JE, Houghton A Jr, Kirkwood JM, McMasters KM, Mihm MF, Morton DL, Reintgen DS, Ross MI, Sober A, Thompson JA, Thompson JF: An evidence-based staging system for cutaneous melanoma. CA Cancer J Clin 2004;54:131-149. 